\title{
ESTRUTURA POPULACIONAL E FECUNDIDADE DE UPOGEBIA OMISSA (DECAPODA: GEBIIDEA: UPOGEBIIDAE) EM UMA REGIÃO ESTUARINA EM SERGIPE, NORDESTE DO BRASIL
}

\author{
Silva, L.F.S. ${ }^{1}{ }^{*} ;$ Santos, B. ${ }^{1}$; Santos, R.C. ${ }^{2}$; Motta, J. M. ${ }^{1}$ \& Alves, D.F.R. ${ }^{2}$ \\ ${ }^{1}$ Universidade Federal de Sergipe (UFS), Campus São Cristóvão 49100 -000 , Sergipe, Brasil. Departamento de \\ Biologia. \\ ${ }^{2}$ Universidade Estadual Paulista (Unesp), Faculdade de Ciências, Campus Bauru 81531 -980, São Paulo, Brasil. \\ LABCAM (Laboratório de Biologia de Camarões Marinhos e de Água Doce). \\ *Autor correspondente: sfilipe015@gmail.com
}

Camarões de lama, pertencentes à infraordem Gebiidea de Saint Laurent, 1979, são importantes componentes das comunidades que habitam os fundos não consolidados de ambientes estuarinos e marinhos. Neste tipo de substrato, a maioria das espécies da família Upogebiidae Borradaile, 1903 escava e habita tocas, que comumente formam galerias complexas. Assim, estes animais exercem um importante papel ecológico devido as atividades de bioturbação do sedimento, podendo ocasionar um aumento da oxigenação do substrato e consequentemente influenciar na composição e densidade dos organismos de comunidades bentônicas. O presente estudo teve como objetivo avaliar parâmetros da estrutura populacional e biologia reprodutiva do camarão de lama Upogebia omissa Gomes Corrêa, 1968, sendo este o primeiro a descrever informações populacionais para esta espécie no litoral brasileiro. Os animais foram amostrados na região estuarina do rio Vaza-Barris, situada no estado de Sergipe, nordeste do Brasil. Em laboratório, os espécimes tiveram o comprimento da carapaça (CC) mensurado, bem como o sexo identificado. As fêmeas ovígeras tiveram seus ovos contados e classificados quanto ao estágio de desenvolvimento do embrião (I, II, ou III). No total, 96 exemplares de U. omissa foram amostrados, 33 machos e 66 fêmeas. A razão sexual foi de 0,34, desviada para as fêmeas (teste binomial, $P=0,001$ ). O comprimento da carapaça (CC) variou entre 3,26 e 12,31 mm. Machos foram significativamente menores que as fêmeas (Mann-Whitney, $U=729.000, P=0.03$ ). A fecundidade variou de 240 a 2339 ovos por fêmea, com média $( \pm \mathrm{DP})$ de $976 \pm 657$ ovos. Foi verificado que o tamanho do corpo afeta significativamente a fecundidade $(\mathrm{F}=$ 37.57 , d.f. $1, \mathrm{P}<0.001)$. O Dimorfismo sexual evidenciado pelo tamanho médio de cada sexo é um padrão comum em decápodes que incubam ovos, nesse caso, a fecundidade normalmente varia em função do tamanho do corpo. Considerando o comportamento intraespecífico agressivo dos Upogebiidae, sugere-se que a razão sexual registrada seja, também, um efeito da competição entre machos por fêmeas reprodutivas, causando por consequência uma mortalidade diferencial entre os sexos. Finalmente, sugere-se que estudos adicionais relacionados à biologia e ecologia dos Upogebiidae sejam elaborados, visto que tais camarões desempenham um papel chave nas comunidades bentônicas de fundos não consolidados e a quantidade de informações sobre os mesmos ao longo da costa brasileira ainda é escassa.

Palavras-chave: camarão de lama, dimorfismo sexual, estuário, fecundidade, Sergipe. 